\title{
Avaliação da proposta de análise documental de textos narrativos de ficção
}

\author{
Evaluation of a methodological proposal for the documental analysis of narrative fiction texts
}

\author{
João Batista Ernesto de Moraes (1), Alessandra Damazo (2) y Lívia Motta de LaRA (3)
}

(1) Faculdade de Filosofia e Ciências, Unesp, Av. Higyno Muzzi Filho, 737, Marília, São Paulo, Brasil, CEP: 17525-900, jota@marilia.unesp. br (2) bem@univem.edu.br (3) liviamottadelara@yahoo.com.br

\begin{abstract}
Resumen
En el momento en que la "materia prima" de la Análisis Documental consiste en textos narrativos de ficción, la complejidad aumenta considerablemente, pues el modelo metodológico de identificación de conceptos elaborado para textos científicos no se aplica a tales textos. Damazo (2006) en la intención de contribuir teóricamente con el desarrollo de un método que facilite la tarea de levantamiento de temas de textos narrativos de ficción, buscó apoyos teóricos en áreas de interfaz con la Ciencia de la Información, más específicamente la Lingüística, y obtuvo como resultados la identificación de temas principales y secundarios en los textos analizados, y así consideró que las fases de manipulación y de sanción de la Secuencia Canónica, contemplan la localización del tema en la estructura del texto narrativo de ficción. De esta manera, este estudio tuvo por objetivo comprobar la aplicabilidad de la utilización del Recorrido Generativo de Sentido como metodología de análisis para la identificación del tema de textos narrativos de ficción y, así, verificar la hipótesis presentada por Damazo (2006). Como procedimiento metodológico, se partió del análisis de las Tesinas Finales realizados en el año de 2006 que utilizaron la identificación de tal secuencia como metodología de análisis para la identificación del tema de textos narrativos de ficción. Como resultado, se obtuvo la comprobación de la posibilidad de identificar el tema general de los textos narrativos de ficción analizados, y concluir con la confirmación de la hipótesis presentada por Damazo (2006).
\end{abstract}

Palabras clave: Texto narrativo de ficción. Tematicidad. Recorrido generativo de sentido. Recorrido temático. Recorrido figurativo. Análisis documental.

\section{Introdução}

Tradicionalmente, a Análise Documental (AD) dá ênfase ao texto científico como paradigma documental para o tratamento de conteúdo. Esta prática se encontra amplamente difundida na tradição da Biblioteconomia e Ciência da Informação, fornecendo o substrato para o delineamento de seus procedimentos técnicos.

Portanto, torna-se necessário investigar as possibilidades metodológicas para fazer frente à $A D$

\begin{abstract}
At the moment that the Documental Analysis "row material" consists of narrative fiction texts, the complexity increases considerably, because the methodological model of concepts identification made to scientific texts do not apply to these texts. Damazo (2006) with a view to contribute theoretically with the development of a method that facilitates the subjects survey task of narrative fiction texts, in its aspects of identification and election of concepts, searched for theoretical subsidies in areas of interface with the Information Science, more specifically the Linguistics, and got as results the identification of main and secondary subjects in the analyzed texts and, thus she considered that the phases of manipulation and sanction of the Canonic Sequence contemplate the subject localization in the structure of the narrative fiction text. So, this study had the objective of investigating the applicability of the Generative Sense Course utilization as methodology of analysis for the subject identification of narrative fiction texts and, thus, to inquire the hypothesis presented by Damazo (2006). As methodological procedure, we started from the analysis of the Final Thesis carried out in 2006 that used the identification of such sequence as methodology of analysis for the subject identification of narrative fiction texts. As result, was given the evidence of the possibility of identifying the general subject of analyzed narrative fiction texts, and to conclude wih the confirmation of the hypothesis presented by Damazo (2006).
\end{abstract}

Keywords: Narrative fiction text. Thematicity. Generative sense course. Thematic course. Figurative course. Document analysis.

de textos narrativos de ficção (1) e, desta forma, contribuir com o universo teórico-metodológico da área.

A questão da análise dos textos narrativos de ficção pressupõe um resgate de aspectos anteriormente abordados no âmbito da lingüística, relativamente à questão de Semiótica narrativa e discursiva, advinda de estudos de A. J. Greimas $(1973,1986)$ e um grupo de pesquisadores na Escola de Altos Estudos em Ciências Sociais em Paris No Brasil dentre os estudiosos dessa 
concepção da Semiótica optou-se por utilizar pesquisadores como Tatit (2003) e Fiorin (1999), que apresentam uma afinidade bastante significativa no âmbito dessas abordagens teóricas

Damazo (2006, p. 81), a partir dos estudos de Moraes e Guimarães (2006 e 2007), elaborou um modelo para facilitar ao indexador a tarefa de análise de assunto de texto narrativo de ficção, com fins de indexação, uma vez que, na literatura da área de Análise Documental há uma carência de estudos teóricos e metodológicos sobre a indexação de textos narrativos de ficção.

Em seu trabalho, Damazo (2006) realizou a identificação da estrutura do texto narrativo de ficção e a identificação da Seqüência Canônica, desses textos. Foram analisados três contos espíritas ( $A$ casca de banana, $O$ devoto desiludido e Mãos enferrujadas) da autoria de Francisco Cândido Xavier. E, como opção estratégica, a partir dessas identificações, o uso do Percurso Temático e do Percurso Figurativo para a análise de assunto visando à obtenção do tema principal e dos temas secundários que poderiam ser indexáveis.

Ao término de seu trabalho, Damazo (2006, p. 82) sugeriu o prosseguimento da sua pesquisa para aprimorar o modelo elaborado e fundamentar teoricamente os aspectos referentes à localização do tema na estrutura do texto narrativo de ficção. Pois, segundo Fiorin (1999, p. 10) as fases de manipulação e de sanção da Seqüência Canônica constituem a dimensão cognitiva da narrativa e enquadram sua dimensão pragmática.

Então, percebeu-se que um estudo mais minucioso destas fases da Seqüência Canônica dos textos narrativos de ficção poderia gerar subsídios que permitiriam identificar em qual destas fases encontra-se localizado o tema principal da narrativa e a partir daí direcionar a análise de assunto (Damazo, 2006, p. 82).

Pelo estudo realizado, pode-se perceber que, na Seqüência Canônica, a fase de manipulação e a de sanção concentram as informações mais relevantes do conteúdo da narrativa e, devido a isto, poderia ser focalizada e direcionada, nestas duas fases, a atenção maior do indexador ao fazer a leitura documental para a análise de assunto. Porém, para confirmar esta hipótese faz-se necessário uma investigação teórica e exemplificações práticas sobre a localização do tema nos textos narrativos de ficção com ênfase nas fases de manipulação e de sanção da Seqüência Canônica (Damazo, 2006, p. 82).
Mediante a confirmação desta hipótese, ou seja, que a fase de manipulação e de sanção possam bastar para realizar a indexação do texto narrativo de ficção, o modelo de análise de assunto para texto narrativo de ficção, proposto nesse trabalho, ficaria muito mais rápido e prático, resultando numa indexação ainda mais eficiente (Damazo, 2006, p. 82).

Nesta perspectiva, aponta-se como problema verificar a hipótese apresentada por Damazo (2006) a qual considera as fases de manipulação e de sanção da Seqüência Canônica, como a localização do tema na estrutura do texto narrativo de ficção.

$\mathrm{Na}$ medida em que tal constatação se faz presente, emerge como proposição deste trabalho fundamentar, por meio de uma investigação teórica e exemplificações práticas a localização do tema na estrutura do texto narrativo de ficção nas fases de manipulação e de sanção da Seqüência Canônica, analisando-se os Trabalhos de Conclusão de Curso (TCC's) de alunos de Biblioteconomia da Faculdade de Filosofia e Ciências (FFC) da Universidade Estadual Paulista (UNESP) - Campus de Marília, realizados no ano de 2006 (Guedes, 2006 e Zambrano, 2006), que utilizaram a identificação de tal seqüência como metodologia de análise para a identificação do tema de textos narrativos de ficção.

Como objetivo geral pretendeu-se explorar a colaboração existente entre a Análise Documental e a Lingüística, mais especificamente o Percurso Gerativo de Sentido. Já como objetivos específicos, pretendeu-se investigar a aplicabilidade da identificação da Seqüência Canônica como metodologia de análise para a identificação do tema de textos narrativos de ficção; analisar os TCC's de alunos de Biblioteconomia, realizados no ano de 2006; apresentar as contribuições destes trabalhos para a Análise Documental; e verificar a possibilidade do tema na estrutura do texto narrativo de ficção estar localizado nas fases de manipulação e de sanção da Seqüência Canônica.

Tal análise ocorreu da seguinte forma: a identificação das fases de manipulação e de sanção da Seqüência Canônica dos textos narrativos de ficção, analisados pelos TCC's foram transcritas e os subtemas identificados nestas fases foram comparados com os temas gerais identificados nos textos analisados, para a verificação da possível correspondência, ou não, entre eles, proporcionada pela isotopia, ou mesmo da possível igualdade, ou não, entre eles.

O primeiro TCC analisado foi Análise do percurso temático e figurativo nas músicas de Chi- 
co Buarque no período de 1968 a 1978, o qual investigou a necessidade de metodologias adequadas, para que o profissional da informação identificasse os temas de uma obra de forma apropriada, buscando subsídios para o estabelecimento do tema.

Com a proposta de analisar, por meio do Percurso Temático e do Percurso Figurativo, as músicas de Chico Buarque do período de 1968 a 1978, objetivando identificar os temas destas canções e, assim, contribuir com a investigação de técnicas adequadas que o profissional da informação tanto necessita para identificar os temas que, posteriormente, seriam utilizados na classificação e indexação (Zambrano, 2006, p. 10).

Como objeto de análise, foram utilizadas canções do compositor Chico Buarque de Holanda compostas nos anos marcados pela Ditadura Militar, mais especificamente, de 1968 a 1978. As canções selecionadas foram consideradas "músicas de protesto", já que o período foi considerado o mais violento e repressor do regime militar. As canções selecionadas foram abordadas apenas como "letras", ou seja, na dimensão de poemas, não foi considerada a parte musical (Zambrano, 2006, p. 31).

Já o segundo TCC analisado foi o intitulado Análise Documentária e a Semântica Discursiva: uma proposta de análise temática em foIhetos de Cordel, o qual propôs o estudo da tematicidade, utilizando como objeto de análise obras de literatura de folhetos nordestina (Literatura de Cordel), buscando analisar estas obras de forma a identificar os temas explorados por seus autores que poderiam subsidiar a proposição de termos que melhor representariam estes temas.

A análise foi efetuada por meio dos recursos oferecidos pela Semântica Discursiva, visando a auxiliar o leitor profissional, principalmente, o não-familiarizado com esta modalidade narrativa, na identificação de temas e na criação ou inclusão destas obras em bases ou catálogos de referência e busca, especializados ou não. (Guedes, 2006, p. 15-16). Foi utilizada, para a análise, a obra intitulada As proezas de um namorado mofino do autor Leandro Gomes de Barros, retirada da seção de obras raras da FFC/UNESP - Campus de Marília (Guedes, 2006, p. 45) (2).

Desta forma, por meio da análise dos TCC's, também foi averiguada a hipótese, proposta por Damazo (2006), da localização do tema, na estrutura do texto narrativo de ficção, nas fases de manipulação e de sanção da Seqüência Canônica. $E$ foram apresentadas as contribuições dadas pelos TCC's analisados para a Análise
Documental e a possível confirmação da hipótese apresentada por Damazo (2006) acima descrita.

Este trabalho apóia-se na contribuição que será oferecida para a Análise Documental, por meio da interdisciplinaridade proporcionada pela interface com a Lingüística, mais especificamente com o Percurso Gerativo de Sentido, demonstrando que a operação de análise dentro do processo de Análise Documental precisa discernir as diferentes estruturas textuais e as metodologias de identificação do tema. Além disso, há a intenção não apenas do fornecimento de subsídios para as práticas profissionais de Biblioteconomia, bem como da contribuição para que se diminua a carência de estudos teóricos e metodológicos na literatura da área de Análise Documental, que normalmente privilegia apenas a análise de textos científicos, sobre a identificação do tema de textos narrativos de ficção.

\section{Análise das músicas de Chico Buarque realizada por Zambrano (2006)}

\subsection{Sabiá (Chico Buarque e Tom Jobim, 1968)}

Os subtemas identificados nas fases de manipulação e de sanção, apesar de não serem coincidentes com o tema geral "exílio", levam a ele, pois "desejo de voltar à terra natal", "mudança de vida" e "fim da tristeza" revelam a isotopia relacionada ao exílio, ou seja, ocorre a recorrência do mesmo traço semântico ao longo do texto, sendo possível identificar o tema geral do texto, por meio dos seus subtemas localizados nas fases de manipulação e de sanção.

\begin{tabular}{c}
\hline Manipulação \\
\hline Vou voltar \\
Sei que ainda vou voltar \\
Para o meu lugar \\
Foi lá e é ainda lá \\
Que eu hei de ouvir cantar \\
Uma sabiá
\end{tabular}

Fonte: Zambrano, 2006, p. 31.

\begin{tabular}{cc}
\hline Temas & Figuras \\
\hline Vou voltar \\
\hline meu lugar \\
\hline lá \\
\hline ouvir cantar \\
\hline sabiá \\
\hline
\end{tabular}

Fonte: Zambrano, 2006, p. 32.

Subtema: desejo de voltar à terra natal. 


\begin{tabular}{c}
\hline Sanção \\
\hline Vou voltar \\
Sei que ainda vou voltar \\
E é pra ficar \\
Sei que o amor existe \\
Eu não sou mais triste \\
E que a nova vida \\
Já vai chegar \\
E que a solidão \\
Vai-se acabar \\
Hei de ouvir cantar \\
Uma sabiá
\end{tabular}

Fonte: Zambrano, 2006, p. 33.

\begin{tabular}{cc}
\hline Temas & Figuras \\
\hline $\begin{array}{c}\text { Oou voltar } \\
\text { pra ficar } \\
\text { não sou mais } \\
\text { triste } \\
\text { nova vida }\end{array}$ & \\
solidão & chegar \\
& Vai-se acabar \\
& ouvir cantar \\
& Uma sabiá \\
\hline
\end{tabular}

Fonte: Zambrano, 2006, p. 33.

Subtemas: mudança de vida / fim da tristeza.

Tema geral: exílio.

\section{Análise do tema em folhetos de cordel, realizada por Guedes (2006)}

\subsection{As proezas de um namorado mofino}

\begin{tabular}{l}
\hline Manipulação \\
\hline Zé-Pitada, rapaz auto-proclamado \\
valente, combina fugir com Marocas, \\
moça por quem era apaixonado, para \\
viverem longe do pai dela, João-Mole \\
"um velho perigoso". \\
Zé-Pitada afirma que o velho fugiria com \\
medo; e afirma suas proezas de \\
valentia.
\end{tabular}

Fonte: Guedes, 2006, p. 47.

\begin{tabular}{cc}
\hline Temas & Figuras \\
\hline adotei a doutrina & cara do homem \\
& o coração \\
\hline enorme distinção & a palavra e a obra \\
Amava muito & O pai dela não
\end{tabular}

queria

vivia sofrendo

moça era como

um pássaro

privado da liberdade

Fonte: Guedes, 2006, p. 47.

Subtemas: mentira sobre valentia / privação da liberdade / sedução.

\begin{tabular}{l}
\hline \multicolumn{1}{c}{ Sanção cognitiva } \\
\hline Zé-Pitada acreditando na mentira da \\
moça demonstra sua vontade de estar \\
na cadeia ao invés de estar naquela \\
situação; chega a recusar um beijo da \\
moça que em um momento tenta \\
consolá-lo.
\end{tabular}

Fonte: Guedes, 2006, p. 48.

\begin{tabular}{cc}
\hline Temas & Figuras \\
\hline lavrar-me a & febre me atacou \\
sentença & Sinto frio \\
d'uma morte tão & horrivelmente \\
feia & ...] Antes eu hoje \\
& estivesse \\
& Encerrado na \\
& cadeia [...] \\
se tem melhora & quer um beijo? \\
desejo-me ir & Beijo não me salva \\
embora & a vida \\
\hline
\end{tabular}

Fonte: Guedes, 2006, p. 48.

Subtemas: medo / covardia.

\begin{tabular}{l}
\hline Sanção pragmática \\
\hline Por fim, a moça decide contar a verdade \\
e expulsá-lo de sua casa, se recusando \\
a conviver com um covarde; \\
O rapaz afirma não mais querer nenhu- \\
ma moça.
\end{tabular}

Fonte: Guedes, 2006, p. 49.

\begin{tabular}{cc}
\hline Temas & Figuras \\
\hline ainda não veio & Meu pai \\
& estou sozinha \\
aí se ergueu & Zé-Pitada \\
E disse & oh minha santinha \\
Expulsão & A moça meteu-lhe \\
& o pé \\
\hline & vai-te murrinha
\end{tabular}




\begin{tabular}{cc} 
crime descomunal & covardia para mim \\
exclama chorando & E lá foi nosso \\
& rapaz \\
& Se arrastando \\
& com a lata \\
juro por Deus & uma moça \\
eu digo & olhar para mim \\
vá embora & Desgraçada. \\
\hline
\end{tabular}

Fonte: Guedes, 2006, p. 49.

Subtemas: medo / covardia / castigo / expulsão.

Temas gerais: medo / covardia / mentira / castigo.

Os subtemas identificados na fase de sanção cognitiva e três dos quatro subtemas identificados na fase de sanção pragmática são coincidentes com três dos quatro temas gerais identificados no texto, fato que mais fortemente confirma a hipótese apresentada por Damazo (2006). Já os subtemas identificados na fase de manipulação e o quarto subtema identificado na fase de sanção pragmática, mesmo não coincidentes com os temas gerais "medo", "covardia", "mentira" e "castigo", levam a eles, pois "mentira sobre valentia", "privação da liberdade", "sedução" e "expulsão" revelam a isotopia relacionada ao medo, covardia, mentira e castigo, ou seja, ocorre a recorrência do mesmo traço semântico ao longo do texto, sendo possível identificar os temas gerais do texto, por meio dos seus subtemas localizados nas fases de manipulação e de sanção.

\section{Considerações Finais}

Tendo em vista os objetivos deste estudo, considera-se que se explorou a colaboração entre a Análise Documental e a Lingüística, mais especificamente o Percurso Gerativo de Sentido, por meio da utilização da identificação da Seqüência Canônica como metodologia de análise para a identificação do tema de textos narrativo de ficção.

Também, confirmou-se a possibilidade do tema, na estrutura do texto narrativo de ficção, estar localizado nas fases de manipulação e de sanção da Seqüência Canônica, o que comprova a hipótese apresentada por Damazo (2006), a qual considera as fases de manipulação e de sanção como a localização do tema na estrutura do texto narrativo de ficção, fato que torna a operação de identificação do tema mais rápida e prática.

É importante ressaltar que a subjetividade e o conhecimento prévio dos autores dos TCC's analisados podem ter influenciado nos resulta- dos das análises por eles realizadas, porém tal fato não anula a confirmação da hipótese apresentada por Damazo (2006) e também não inviabiliza a utilização da identificação da Seqüência Canônica como metodologia de análise para a identificação do tema de textos narrativos de fiç̧ão, pois os temas identificados, da mesma forma, poderiam ter sido identificados por bibliotecários não-familiarizados com os tipos de textos analisados, por meio do uso do Percurso Gerativo de Sentido, mais especificamente da identificação da Seqüência Canônica.

Destaca-se, também, que para o uso da identificação da Seqüência Canônica como metodologia de análise para a identificação do tema de textos narrativos de ficção torna-se necessária a compreensão dos fundamentos do Percurso Gerativo de Sentido, no entanto, entende-se que esta necessidade não se torna um empeciIho a utilização desta metodologia, considerando o enriquecimento que será proporcionado ao bibliotecário a partir do conhecimento de uma nova área.

Para finalizar recomenda-se o prosseguimento deste trabalho, uma vez que não houve a intenção de encerrar os assuntos tratados, mas sim de propor a aplicação de uma metodologia e, a partir disso, levantar novos questionamentos, para assim aprofundar a colaboração entre a Análise Documental e a Lingüística, mais especificamente o Percurso Gerativo de Sentido e aperfeiçoar a metodologia de análise para a identificação do tema de textos narrativos de ficção, neste trabalho, comprovada, para que a mesma se torne ainda mais rápida e prática.

\section{Notas}

(1) A referência específica ao texto narrativo de ficção dá-se em virtude de uma especificidade que lhe é própria, pois, por ser mais permeável às figuras de linguagem, tais como a metáfora, apresenta maior complexidade na determinação do tema, se comparado, por exemplo, com o texto narrativo não ficcional, como a notícia de jornal, em que o lead, por si só, fornece importantes elementos para o processo de análise temática.

(2) Texto escrito pelo autor Leandro Gomes de Barros (1865-1918) e retirado do portal Domínio Público (www.dominiopublico.gov.br).

\section{Referências}

Damazo, A. C. (2006). Análise de assunto de conto espírita por meio do percurso figurativo e do percurso temático. 2006. Marília, Faculdade de Filosofia e Ciências: Universidade Estadual Paulista, 2006. Dissertação de Mestrado em Ciência da Informação.

Fiorin, J.L. (1999). Sendas e veredas da semiótica narrativa e discursiva. // Delta. 15:1 (1999). www.scielo.br em: 25 set. 2006. 
Greimas, A. J.; Courtés, J. (1986). Dicionário de semiótica. São Paulo: Cultrix, 1986.

Greimas, A. J. (1973). Semântica estrutural. São Paulo: Cultrix, 1973.

Guedes, E. G. F. (2006). Análise documentária e semântica discursiva: uma proposta de análise temática de folhetos de cordel. Marília: Faculdade de Filosofia e Ciências, Universidade Estadual Paulista, Marília, 2006. Trabalho de Conclusão de Curso de Graduação em Biblioteconomia.

Moraes, J. B. E.; Guimarães, J. A. C. (2006). Análisis documental de contenido de textos literarios narrativos: en busca del diálogo entre las concepciones de aboutness/meaning y de recorrido temático/recorrido figurativo. // Scire. 12 (2006) 120-135.

Moraes, J. B. E.; Guimarães, J.A.C.; Guarido, M.D.M. (2007). Análisis documental de contenido de textos narrativos: bases epistemológicas y perspectivas metodológicas. // García Marco, F.J. (Org.). Avances y perspectivas en sistemas de información y documentación en entorno digital. Zaragoza: Prensas Universitarias de Zaragoza, 2007. 93-100.

Tatit, L. Abordagem do texto. Fiorin, J. L. (Org.). Introdução à Lingüística: I. São Paulo: Contexto, 2003. p. 187-209.

Zambrano, N. R. (2006). Análise do percurso temático e figurativo nas músicas de Chico Buarque de Holanda no período de 1968 a 1978. Marília: Faculdade de Filosofia e Ciências - Universidade Estadual Paulista, 2006. Trabalho de Conclusão de Curso de Graduação em Biblioteconomia. 